\title{
Utility of Japan Narrow Band Imaging Expert Team Classification Using Narrow Band Imaging for Evaluation of Colonic Polyps
}

\author{
Dipak S. Ahire ${ }^{1}$ Pravin M. Rathi ${ }^{1} \quad$ Niranjan H. Banka ${ }^{1}$ Parth K. Shah ${ }^{1}$ \\ 1Department of Gastroenterology, Bombay Hospital and Institute of \\ Medical Sciences, Mumbai, Maharashtra, India \\ Address for correspondence Dipak S. Ahire, MBBS, MD, DNB, \\ Department of Gastroenterology, Bombay Hospital and Institute \\ of Medical Sciences, Mumbai 400020, Maharashtra, India \\ (e-mail: dipakahire33@gmail.com).
}

J Digest Endosc 2020;11:138-145

\begin{abstract}
Keywords

- narrow-band imaging

- colonic polyps

- surface pattern

- vessel pattern

Background Narrow band imaging (NBI) is an advanced endoscopic imaging technique that enhances visualization of the mucosal surface and is used as a screening tool for colonic polyps. Its usefulness is currently explored to a lesser extent in India. So, we assessed the utility of Japan NBI Expert Team (JNET) classification for characterization of colorectal polyps.

Methods A prospective observational study was performed from January 2018 to June 2019 of patients undergoing colonoscopy at a tertiary care hospital. NBI image of polyps was captured followed by either polypectomy/biopsy. Histopathology results were correlated with the pattern revealed by NBI on polyps using the JNET classification. Results A total of 80 patients, 61(76.25\%) male with a mean (standard deviation [SD]) age of $58.41 \pm 14.59$ years were included. Out of the 90 lesions, 23 (25.5\%) had type-1 pattern, $45(50 \%)$ had 2A, $13(14.4 \%)$ had 2B, and $9(10 \%)$ had type-3 pattern. On histopathology, majority 51 (59.3\%) were found to be adenomatous with low-grade intramucosal neoplasia. When correlating our results with JNET category type 1 and hyperplastic polyps, the sensitivity was $90 \%$, specificity was $97 \%$, negative predictive value was $97 \%$, positive predictive value was $90 \%$, and diagnostic accuracy was $96 \%$. Correlating type $2 \mathrm{~A}$ and low-grade intramucosal neoplasia had results of 78 , $87,76,90$, and $82 \%$, respectively. Correlating type $2 B$ and high-grade intramucosal neoplasia had results of $83,90,99,38$, and $90 \%$, respectively. Correlating type 3 and deep submucosal cancer had results of $88,98,99,78$, and $97 \%$, respectively.

Conclusion NBI shows excellent probability to exclude carcinoma possibilities based on the changes in colonic mucosal features. Owing to slightly lower sensitivity for type $2 \mathrm{~B}$, it needs additional investigation using pit pattern diagnosis. We demonstrated the high-diagnostic performance of NBI in making an accurate diagnosis of early colorectal cancers in colonoscopy. Further refinement in the NBI technology might add to the current evidence for characterization of polyps.
\end{abstract}

\section{Introduction}

Colonic polyps are overgrowths of the colonic mucosa which carry a low risk of becoming malignant and are often encountered during routine standard screening procedures. ${ }^{1}$
Screening helps to detect polyps which can turn malignant in people who have no symptoms of the disease. ${ }^{2}$ Colorectal cancer (CRC) is life-threatening when diagnosed in advanced stages. ${ }^{3}$ Most commonly used screening tool for CRC is colonoscopy. Colonoscopic detection and polypectomy 
represents the most important prevention method for CRC. ${ }^{4}$ The prevalence of adenoma is approximately $10 \%$ in sigmoidoscopy and $>25 \%$ in colonoscopy, whereas the prevalence of CRC among these is $<1 \%{ }^{5}$ The standard colonoscopic procedure uses magnifying chromoendoscopy principle. Narrowband imaging (NBI; Olympus, Japan) was introduced in 1999 and uses optical technology for enhanced images and surface patterns of lesions resulting in better outcomes in terms of detection and early diagnosis of colorectal tumors. ${ }^{6} \mathrm{NBI}$, when combined with magnification colonoscopy, is useful for histological prediction, or for estimating the depth of invasion. ${ }^{7}$ NBI with magnification is useful in differentiating neoplastic from nonneoplastic lesions. Several magnifying NBI classifications for diagnoses of colorectal lesions are developed. ${ }^{8-11}$ Of late, Japan NBI Expert Team (JNET) classification was developed. ${ }^{12}$ But its usefulness in Indian patients is unexplored. So, we aim to study the diagnostic accuracy of the JNET classification and correlate histopathology results with the pattern revealed by NBI in a prospective manner.

\section{Methods}

A prospective observational study was performed from January 2018 to June 2019 of patients undergoing colonoscopy at a super specialty Gastroenterology outpatient and inpatient department of a tertiary care teaching hospital. Inclusion criteria were consecutive patients of either sex of any age group who underwent elective colonoscopy for screening, surveillance or evaluation of symptoms. Patients found to have polyps with white light were followed by subsequent NBI. Exclusion criteria were patients' already diagnosed with colorectal neoplasm, colectomy, polyposis syndrome, past history of Inflammatory Bowel Disease (IBD) with pseudopolyps, and pregnancy. Ethical approval was obtained from institutional ethics committee. Written informed consent was also obtained from all patients prior to the start of study.

Colonoscope (CFQ-180AL, Olympus, Tokyo, Japan) was used for the examination. Each polyp detected was washed free of stool and mucus, and then examined under NBI without magnification. NBI image of polyps was captured followed by either polypectomy or biopsies. Histopathology of biopsy sample was correlated with pattern revealed by NBI on polyps using JNET classification. Data were recorded on a predesigned proforma and real time data entry was done on Microsoft excel for windows. Endoscopic diagnosis was done using JNET classification. JNET types 1, 2A, 2B, and 3 correspond to the histopathological classifications of hyperplastic polyp (HP)/SSP, low-grade intramucosal neoplasia (LGN), high-grade intramucosal neoplasia (HGN)/shallow submucosal (SM-s) invasive cancer, and deep SM (SM-d) invasive cancer, respectively.

\section{Patient Preparation}

An electrolyte-balanced solution (polyethylene glycol) was prescribed to patients to be taken in 2 to $3 \mathrm{~L}$ of water in morning (5-7 a.m.). Patients were asked to drink this preparation every 15 to 20 minutes until the bowel's output was clear or the solution was completely consumed. Colonoscopy was ideally performed between 10 a.m. to 2 p.m.

\section{Histopathology Examination}

Specimens were fixed in $20 \%$ formalin and histologically examined after hematoxylin and eosin staining. Histologic diagnosis was made by a pathologist blinded to the colonoscopic diagnosis at each step.

\section{Statistical Analysis}

Statistical analysis was performed using the Statistical Package for Social Sciences (SPSS) software for windows (v. 21, SPSS, Inc., Chicago, Illinois, United States). The sensitivity, specificity, positive predictive value (PPV), negative predictive value (NPV), and accuracy were calculated for each classification category. The interobserver agreement and the intraobserver agreement were calculated using $\mathrm{k}$ coefficients, using the following arbitrary interpretation reported by Landis and Koch.

- Poor: 0 to 0.20 .

- Fair: 0.21 to 0.40 .

- Moderate: 0.41 to 0.60 .

- Substantial: 0.61 to 0.80 .

- Excellent: 0.81 to 1.00 .

The criterion standard for validation of predictions was the histology of colorectal lesions.

\section{Results}

A total of 80 patients were studied with NBI and histopathology and 90 polyps were identified. There was male predominance 61 (76.25\%) with a mean (standard deviation [SD]) age of $58.41 \pm 14.59$ years. The most common symptom at presentation was abdominal pain in $24(30 \%)$ patients and comorbidity was diabetes mellitus in 21 (23.3\%) patients. Demographic characteristics of patients are given in - Table 1. Most of the polyps were seen in left-sided colon 55 (61.1\%). The mean (SD) size of polyps was $1.32 \pm 1.05 \mathrm{~cm}$. Polyp of size $>1 \mathrm{~cm}$ were seen in 61 (67.77\%) cases. According to Paris classification majority were sessile $62(68.8 \%)$ in nature. Out of the 90 lesions, 23 (25.5\%) had type-1 pattern, 45 (50\%) had 2A, 13 (14.4\%) had 2B, and 9 (10\%) had type-3 pattern. On histopathology, majority 51 (59.3\%) were found to be adenomatous with low grade intramucosal neoplasia (-Table 2).

When correlating our results with JNET category type 1 ( - Fig. 1A) and HPs ( - Fig. 1B), the sensitivity was found to be $90 \%$, specificity was $97 \%$, NPV of $97 \%$, PPV of $90 \%$, and diagnostic accuracy was $96 \%$. Correlating type $2 \mathrm{~A}$ ( - Fig. $2 \mathrm{~A}$ ) and lowgrade intramucosal neoplasia ( - Fig. 2B) had results of 78, 87, 76,90 , and $82 \%$, respectively. Correlating type $2 \mathrm{~B}$ ( - Fig. $3 \mathrm{~A}$ ) and high-grade intramucosal neoplasia (-Fig. 3B) had results of $83,90,99,38$, and $90 \%$, respectively. Correlating type 3 ( - Fig. 4A) and SM-d cancer ( - Fig. 4B) had results of 88, 98, 99, 78, and $97 \%$, respectively (-Table 3 ). The relationship between JNET classification and histology is given in - Table 4 . In this study, the interobserver agreement was seen among 
Table 1 Patient demographics

\begin{tabular}{|c|c|}
\hline Patient characteristics & $n(\%)$ \\
\hline $\begin{array}{l}\text { Total no. of patients } \\
n(\%)\end{array}$ & $80(100)$ \\
\hline Total no. of lesions & 90 \\
\hline Mean \pm SD (y) & $58.41 \pm 14.59$ \\
\hline Male & $61(76.2)$ \\
\hline $\mathrm{M}: \mathrm{F}$ & $3.2: 1$ \\
\hline \multicolumn{2}{|l|}{ Comorbidities, n (\%) } \\
\hline Diabetes mellitus & $21(23.3)$ \\
\hline $\begin{array}{l}\text { Hypertension } \\
\text { Ischemic heart disease }\end{array}$ & $\begin{array}{l}15(16.7) \\
9(10)\end{array}$ \\
\hline Cirrhosis of liver & $3(3.3)$ \\
\hline Carcinoma & $3(3.3)$ \\
\hline Cerebrovascular accident & $2(2.2)$ \\
\hline Chronic kidney disease & $2(2.2)$ \\
\hline Iron deficiency anemia & $2(2.2)$ \\
\hline Immune thrombocytopenic purpura & $1(1.1)$ \\
\hline Abdominal Koch's & $1(1.1)$ \\
\hline \multicolumn{2}{|l|}{ Presenting symptom } \\
\hline Abdominal pain & $24(30)$ \\
\hline Chronic constipation & $22(27.5)$ \\
\hline Chronic diarrhea & $19(23.7)$ \\
\hline Weight loss & $18(22.5)$ \\
\hline Blood in stool & $11(13.7)$ \\
\hline Anemia & $9(11.2)$ \\
\hline Melena & $7(8.7)$ \\
\hline Perianal pain & $5(6.2)$ \\
\hline Mucus in stool & $2(2.5)$ \\
\hline Labial pigmentation & $1(1.2)$ \\
\hline \multicolumn{2}{|l|}{ Clinical examination } \\
\hline Left illiac fossa tenderness & $14(17.5)$ \\
\hline Painful per rectal examination & $6(7.5)$ \\
\hline Right illiac fossa tenderness & $6(7.5)$ \\
\hline Epigastric tenderness & $3(3.7)$ \\
\hline Pallor & $2(2.5)$ \\
\hline Ascites & $1(1.2)$ \\
\hline Hypogastrium tenderness & $1(1.2)$ \\
\hline
\end{tabular}

Abbreviations: F, female; M, male; SD, standard deviation.

the two observers, as kappa values $=0.76$ which suggests substantial agreement (-Table 5). In contrast, the intraobserver agreement was excellent, as kappa values $=0.93$.

\section{Discussion}

By prospectively enrolling patients over 18 months' period in this observational study, we studied the utility of JNET classification for evaluation of colonic polyps and HP results were correlated with the pattern revealed by NBI. We demonstrated the high-diagnostic performance of NBI in making
Table 2 Polyp characteristics along with NBI features

\begin{tabular}{|c|c|}
\hline Patient characteristics & $n(\%)$ \\
\hline \multicolumn{2}{|l|}{ Site of polyp } \\
\hline Ascending colon & $22(24.4)$ \\
\hline Sigmoid & $21(23.3)$ \\
\hline Rectum & $17(18.8)$ \\
\hline Descending colon & $15(16.6)$ \\
\hline Transverse colon & $5(5.5)$ \\
\hline Throughout colon & $5(5.5)$ \\
\hline Cecum & $2(2.2)$ \\
\hline Splenic flexure & $2(2.2)$ \\
\hline Hepatic flexure & $1(1.1)$ \\
\hline \multicolumn{2}{|l|}{ Distribution of polyp in colon } \\
\hline Left sided colon & $55(61.1)$ \\
\hline Right sided colon & $30(33.3)$ \\
\hline Throughout colon & $5(5.5)$ \\
\hline \multicolumn{2}{|l|}{ Polyp morphology } \\
\hline Sessile & $62(68.9)$ \\
\hline Pedunculated & $17(18.9)$ \\
\hline Flat & $11(12.2)$ \\
\hline $\begin{array}{l}\text { Polyp size (Mean } \pm \mathrm{SD} \text { ) } \\
\mathrm{cm}\end{array}$ & $1.32 \pm 1.05$ \\
\hline \multicolumn{2}{|l|}{ Polyp size (cm) } \\
\hline$>1$ & $61(67.8)$ \\
\hline$<0.5$ & $23(25.5)$ \\
\hline $0.6-0.9$ & $6(6.7)$ \\
\hline \multicolumn{2}{|l|}{ NBI as per JNET classification } \\
\hline Type 1 & $23(25.6)$ \\
\hline Type 2A & $45(50)$ \\
\hline Type 2B & $13(14.4)$ \\
\hline Type 3 & $9(10)$ \\
\hline \multicolumn{2}{|l|}{ Histopathology } \\
\hline Hyperplastic & $21(24.4)$ \\
\hline $\begin{array}{l}\text { Low-grade intra- } \\
\text { mucosal neoplasia } \\
\text { (adenomatous) }\end{array}$ & $51(59.3)$ \\
\hline $\begin{array}{l}\text { High-grade intramuco- } \\
\text { sal neoplasia }\end{array}$ & $6(7)$ \\
\hline $\begin{array}{l}\text { Deep submucosal inva- } \\
\text { sive cancer }\end{array}$ & $8(9.3)$ \\
\hline
\end{tabular}

Abbreviations: JNET, Japan NBI expert team; NBI, narrow band imaging; $\mathrm{SD}$, standard deviation.

an accurate diagnosis of early colorectal cancers in colonoscopy. In the present study, majority of the patients were in the age group of 61 to 70 years. Older age appears to have a positive correlation with an increased development of HPs as seen evidently from studies conducted across the world. ${ }^{13,14}$ Another risk factor that differs between serrated colorectal polyps and sessile serrated adenoma or polyp in comparison to conventional adenomas is male sex. ${ }^{15}$ While males clearly have a higher risk of conventional adenomas compared with 

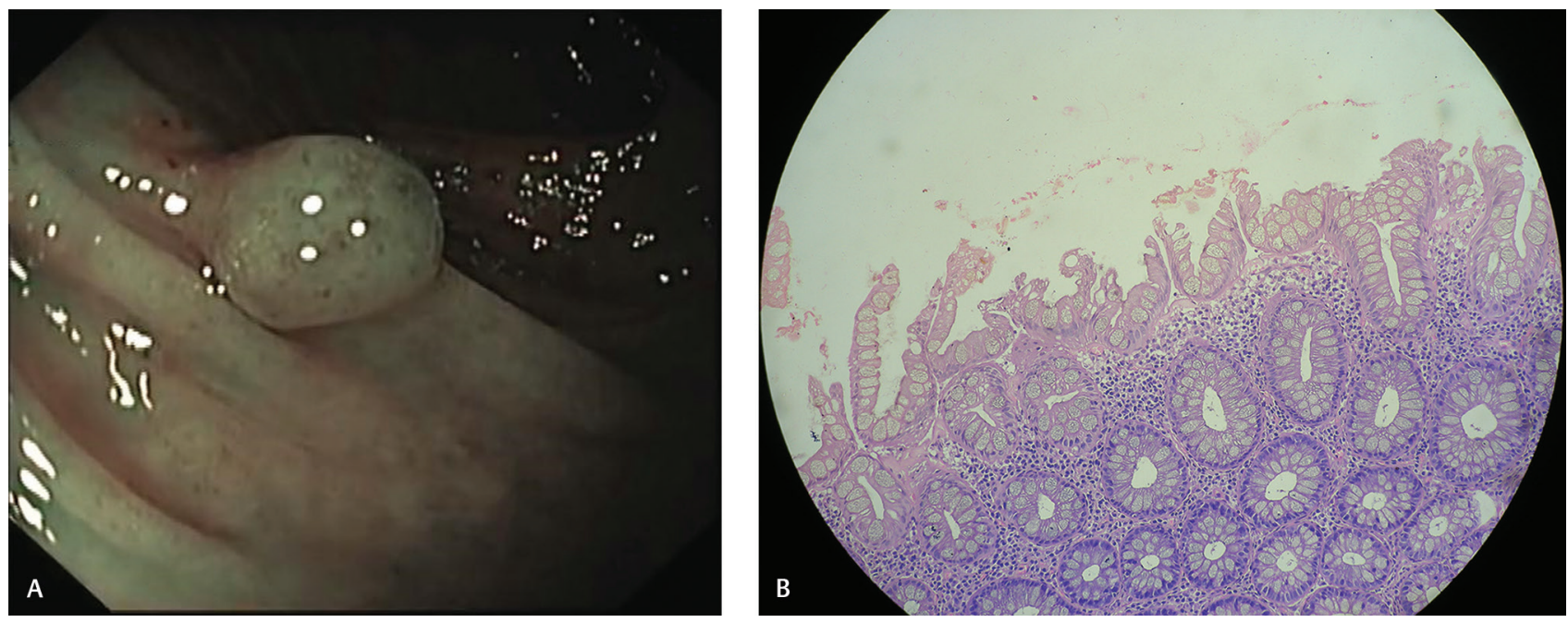

Fig. 1 (A) Vessel pattern is regular, surface pattern is dark and white spot similar to normal mucosa, (×magnification). (B) The crypt lining is irregular, along the surface, deeper down crypts are uniform, mild increase in mononuclear inflammation in lamina propria, histopathology (hematoxylin and eosin stain, $\times 200$ magnification). NBI, narrow band imaging.
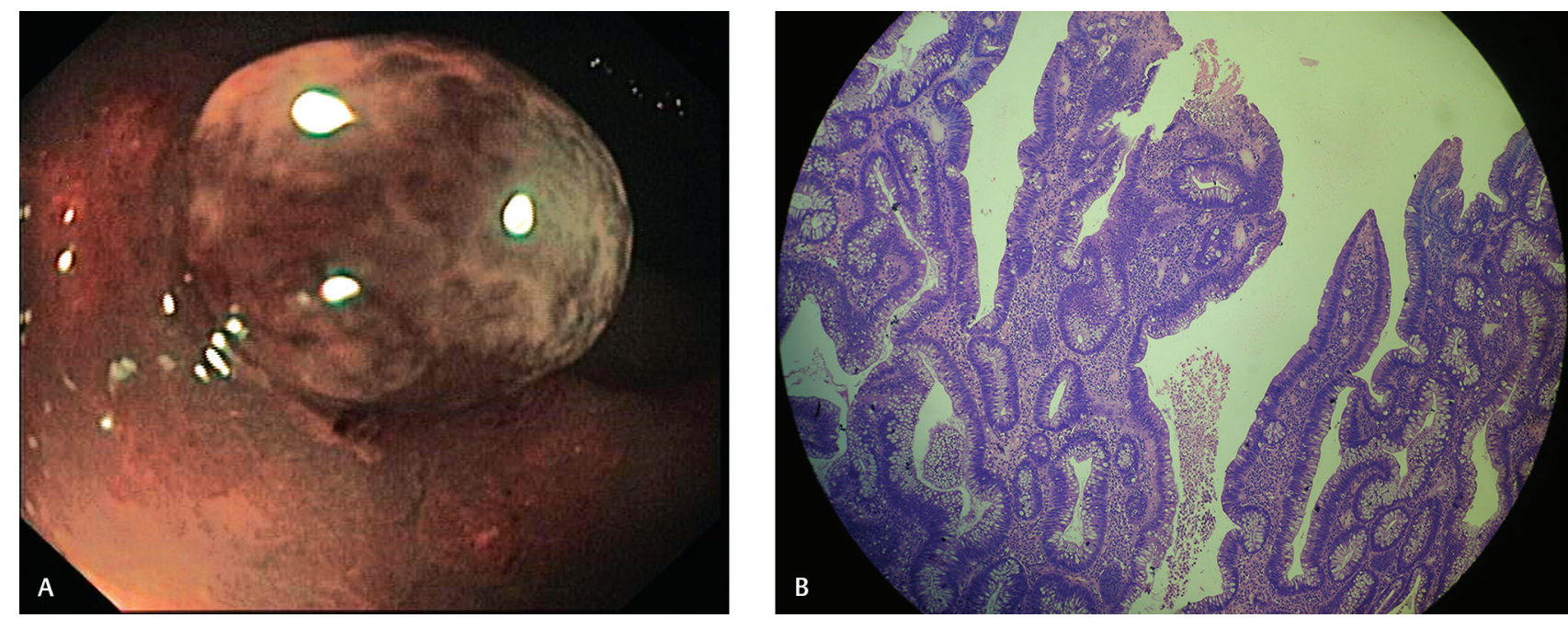

Fig. 2 (A) Vessel pattern is regular distribution and caliber, surface pattern- regular tubular pattern. (×magnification). (B) Surface is tubulovillous configuration, lamina propia contains crowded crypts lined by columnar epithelium with nuclear stratification confined to basal half of cell, (hematoxylin and eosin stain, $\times 200$ magnification). NBI, narrow band imaging.
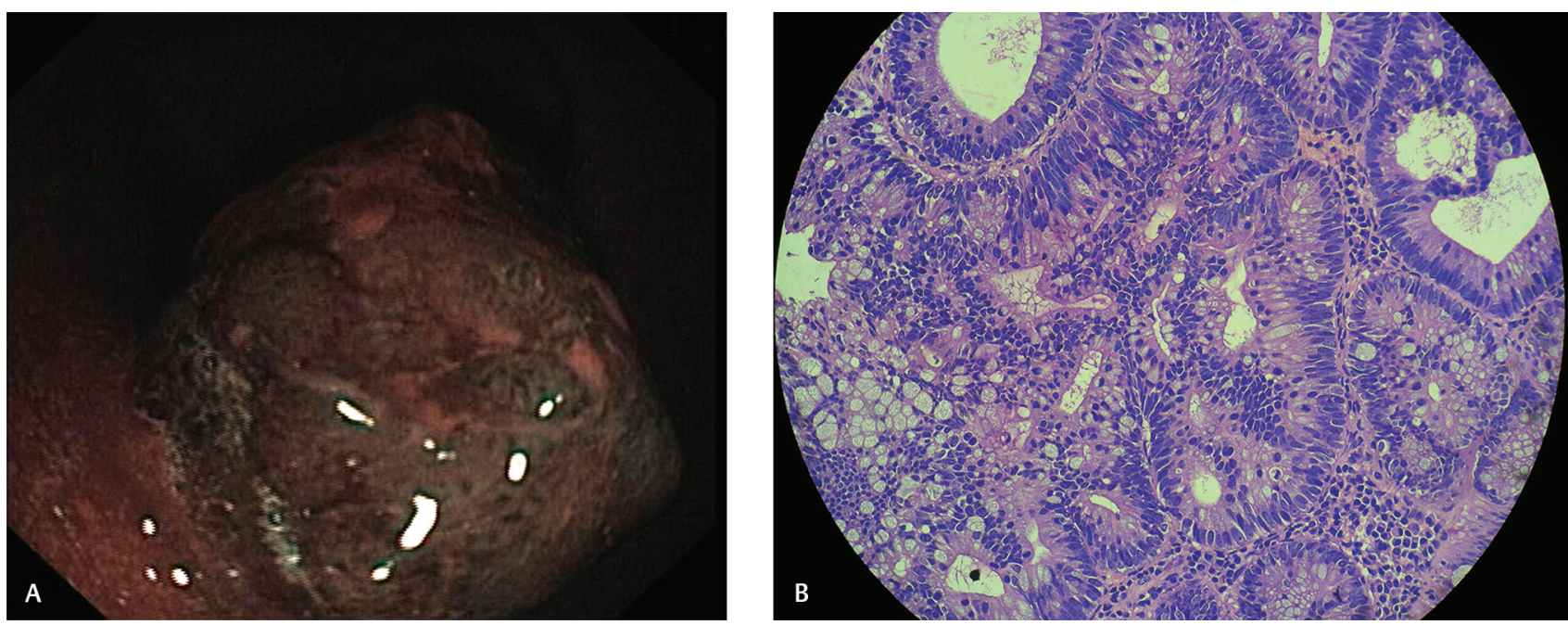

Fig. 3 (A) Vessel pattern is variable pattern and irregular distribution, surface is irregular and obscure. ( $\times 2$ magnification). (B) Crypts are crowded, architecture irregularly, cribri forming, nuclei are oval to elongated, stratified and atypical with hypochromasia, (hematoxylin and eosin stain, $\times 400$ magnification). NBI, narrow band imaging. 

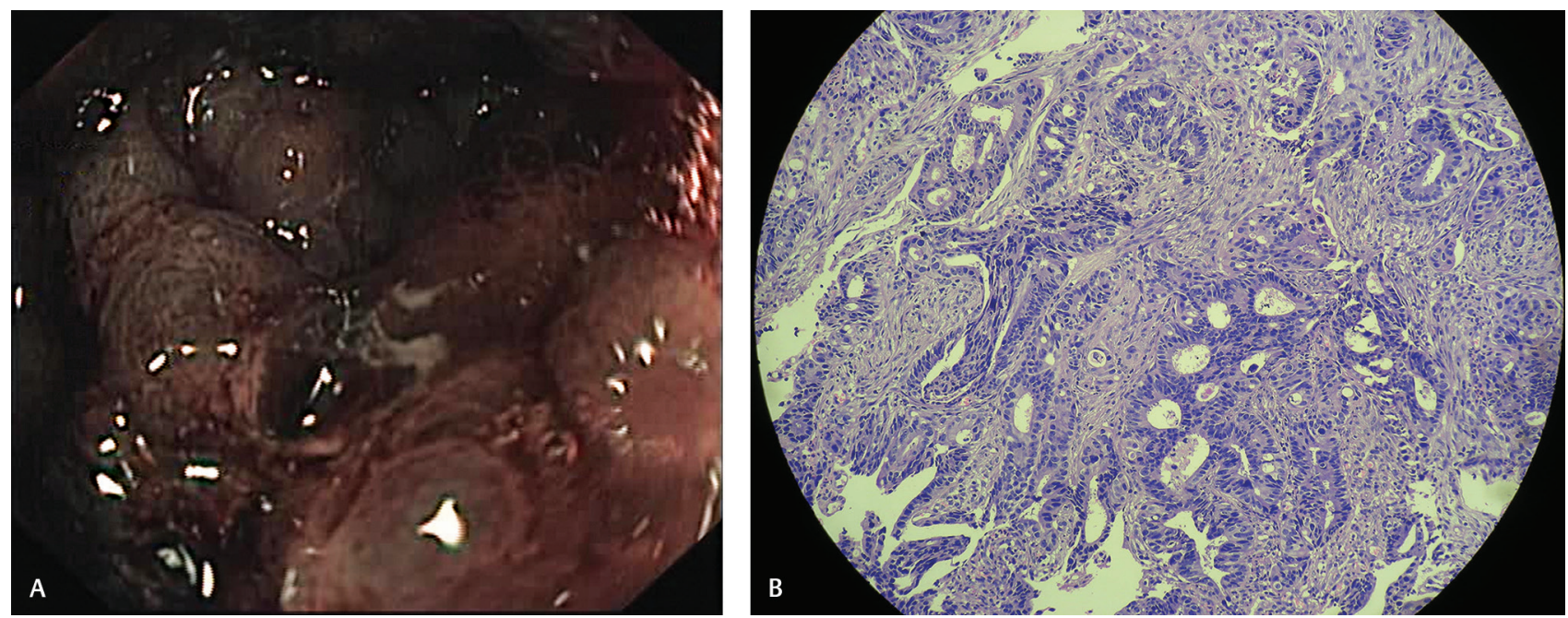

Fig. 4 (A) Vessel pattern-loose vessel area, interruption of thick vessel, amorphous surface pattern, (×magnification). (B) Atypical glands aligned by hyperchromasia, round to oval nuclei with columnar cell, infiltration gland with desmoplastic stroma, (hematoxylin and eosin stain, $\times 200$ magnification). NBI, narrow band imaging.

Table 3 Characteristics (95\% Cl) of each type in JNET classification

\begin{tabular}{|l|l|l|l|l|l|}
\hline JNET class & Sensitivity, $\%$ & Specificity, $\%$ & PPV, $\%$ & NPV, $\%$ & Accuracy, $\%$ \\
\hline Type 1 & $90(71.09-97.35)$ & $97(90.03-99.2)$ & $90(90.03-99.2)$ & $97(71.09-97.35)$ & $96(89.12-98.26)$ \\
\hline Type 2A & $78(65.37-87.51)$ & $87(73.29-94.4)$ & $90(61.33-85.76)$ & $76(76.5-95.16)$ & $82(73.06-88.75)$ \\
\hline Type 2B & $83(43.65-96.99)$ & $90(82.32-95.09)$ & $38(93-99.77)$ & $99(17.71-64.48)$ & $90(82.08-94.65)$ \\
\hline Type 3 & $88(52.91-97.76)$ & $98(91.54-99.33)$ & $78(93.33-99.78)$ & $99(45.26-93.68)$ & $97(90.65-98.86)$ \\
\hline
\end{tabular}

Abbreviations: $\mathrm{Cl}$, confidence interval; JNET, Japan NBI (narrow band imaging) expert team; NPV, negative predictive value; PPV, positive predictive value.

females, the same is not true for serrated colorectal polyps and sessile serrated adenoma or polyp; females are at equal or slightly higher risk of harboring these lesions. ${ }^{16}$ In our study, we had male predominance with 61 (76.25\%), with a male-to-female ratio of 3.2:1, respectively. Similar trend was seen in multiple other studies. ${ }^{15,16}$ Diabetes has been shown to be a risk factor for adenomas in some studies. ${ }^{17}$ Diabetes mellitus was the most common comorbidity seen in $21(23.3 \%)$ of the patients with polyps.

In a German study in 2007 with 90 patients, 102 (51\%) of polyps were seen in the right colon, 69 (34.5\%) in the left colon, and $29(14.5 \%)$ in the rectum. ${ }^{18}$ In a Japanese study in 2010 with 127 patients, 81 (62.3\%) lesions were located in the left colon and rectum and 49 (37.7\%) lesions were located in the right and transverse colon. ${ }^{19}$ Our study had similar findings; most of the polyps were located in the left sided colon and rectum, $55(61.1 \%)$ as compared with right sided colon 30 (33.3\%). One needs to visualize the mucosa of left-sided colon and rectum with proper magnification since chances of finding these lesions are prominent in these areas. The mean size of the polyps was found to be $9.9 \mathrm{~mm}$ (range: $2-50 \mathrm{~mm}$ ) ${ }^{18}$ in 90 patients, while it was $17 \mathrm{~mm}$ (range: $5-80 \mathrm{~mm}$ )with 127 patients in the Japanese study. ${ }^{19}$ Our findings are in line with these as the mean size of polyps in the present study was $1.32 \pm 1.05 \mathrm{~cm}$.

Morphologically, characterization of polyp is usually done with the Paris classification for gastrointestinal polyps. ${ }^{20}$
Polypoid lesions (Paris 0-I), sessile or pedunculated polyps $(>10 \mathrm{~mm})$, have a low-invasive potential $(7 \%)$, whereas as those with a depressed component (either Paris IIc or IIa $+c$ ) have a $31 \%$ risk of SM invasion. ${ }^{21}$ In this study, according to Paris classification most of the polyps found were sessile 62 (68.89\%), other lesions were pedunculated 17 (18.89\%) and flat type in $11(12.22 \%)$ cases.

In the present study, pathological analysis of 90 lesions revealed cases of HP as 21 (24.4\%), 51 (59.3\%) cases of lowgrade dysplasia (LGD), 6 (7\%) cases of high-grade dysplasia (HGD) and 8 (9.3\%) cases of SM-d invasion. In a Japanese study (2010), the pathological analysis of 199 lesions revealed 14 cases of HP/SSP, 127 cases of LGD, 22 cases of HGD, 19 cases of SM-s, and 17 cases of SM-d. ${ }^{22}$ The present study contained 23 patients with type- 1 patterns, out of which 21 (91.3\%) patients had HPs on histology and other two lesions were nonhyperplastic. The actual correlation between type 1 and HPs was seen only in 19 patients, with a sensitivity of $90 \%$, specificity of $97 \%$, and diagnostic accuracy of $96 \%$. Type-2A patterns demonstrated in this study by 45 patients, but according to histopathology low-grade intramucosal adenoma was found in 51 lesions. Out of 45 lesions with type $2 \mathrm{~A}$, only 40 lesions had actual correlation with histology of low-grade intramucosal adenoma, rest of the five lesions could not be identified as having low-grade intramucosal adenoma. 
Table 4 Relationship between JNET classification and histology

\begin{tabular}{|l|l|l|l|l|l|}
\hline \multirow{2}{*}{ JNET Class } & \multicolumn{4}{|c|}{ Histology } & \multirow{2}{*}{ Other } \\
\cline { 2 - 5 } & HP & LGD & HGD & SM-d & \\
\hline Type $1(n=23)$ & $19(82.6 \%)$ & $2(8.7 \%)$ & 0 & 0 & $2(8.7 \%)$ \\
\hline Type 2A $(n=45)$ & $2(4 \%)$ & $40(88 \%)$ & $1(2 \%)$ & $1(2 \%)$ & $1(2 \%)$ \\
\hline Type 2B $(n=13)$ & 0 & $8(61 \%)$ & $5(46.1)$ & 0 & 0 \\
\hline Type 3 $(n=9)$ & 0 & $1(1.1 \%)$ & 0 & $7(77 \%)$ & $1(1.1 \%)$ \\
\hline
\end{tabular}

Abbreviations: HGD, high-grade dysplasia; HP, hyperplastic polyp; JNET, Japan NBI (narrow band imaging) expert team; LGD, low-grade dysplasia; SM-d, deep submucosal invasive cancer.

Table 5 Interobserver agreement for JNET classification

\begin{tabular}{|c|c|c|c|c|c|c|}
\hline \multirow[t]{2}{*}{ Rater 1} & & \multicolumn{4}{|c|}{ Rater-2 } & \multirow[t]{2}{*}{ Total } \\
\hline & & Type 1 & Type 2A & Type 2B & Type 3 & \\
\hline \multirow[t]{2}{*}{ Type 1} & No. & 20 & 3 & 0 & 0 & 23 \\
\hline & $\%$ & 87.00 & 7.00 & 0.00 & 0.00 & 25.60 \\
\hline \multirow[t]{2}{*}{ Type 2A } & No. & 3 & 38 & 4 & 0 & 45 \\
\hline & $\%$ & 13.00 & 88.40 & 23.50 & 0.00 & 50.00 \\
\hline \multirow[t]{2}{*}{ Type 2B } & No. & 0 & 2 & 11 & 0 & 13 \\
\hline & $\%$ & 0.00 & 4.70 & 64.70 & 0.00 & 14.40 \\
\hline \multirow[t]{2}{*}{ Type 3} & No. & 0 & 0 & 2 & 7 & 9 \\
\hline & $\%$ & 0.00 & 0.00 & 11.80 & 100.00 & 10.00 \\
\hline \multirow[t]{2}{*}{ Total } & No. & 23 & 43 & 17 & 7 & 90 \\
\hline & $\%$ & 100.00 & 100.00 & 100.00 & 100.00 & 100.00 \\
\hline $\begin{array}{l}\text { Symmetric } \\
\text { measures }\end{array}$ & & Value & Asymp. SE & Approx. $\mathrm{T}^{\mathrm{b}}$ & Approx. Sig. & \\
\hline $\begin{array}{l}\text { Measure of } \\
\text { agreement }\end{array}$ & Kappa & 0.765 & 0.058 & 11.394 & 0 & \\
\hline No. of valid cases & & 90 & & & & \\
\hline
\end{tabular}

Abbreviations: Approx., approximately; Asymp., asymptomatic; JNET, Japan NBI (narrow band imaging) expert team; SE, standard error; T ${ }^{b}$, using the asymptotic standard error assuming the null hypothesis.

Note: not assuming the null hypothesis.

Using the asymptotic standard error assuming the null hypothesis.

In a recent study of Sumimoto et $\mathrm{al},{ }^{23}$ with 2,933 lesions, the specificity of type $2 \mathrm{~B}$ was found to be $82.8 \%$ and PPV of type $2 \mathrm{~B}$ was $50.9 \%$, significantly lower than those of the other type of JNET. The ability of type $2 \mathrm{~B}$ to identify HGD or SM carcinoma was not significant. These results are somewhat in line with our findings which does not show any significant

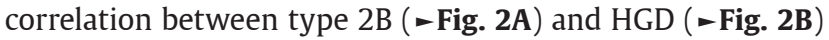
as specificity was $90 \%$ and PPV was $38 \%$. This may be contributed to type $2 \mathrm{~B}$ pattern, which shows various histological findings, ranging from LGD to SM-d carcinoma.

The type-2B pattern was found in 13 (14.4\%) patients, with distributions of 5 lesions with high-grade intramucosal hyperplasia, 7 lesions with low-grade intramucosal neoplasia, and 1 lesion with deep SM cancer with histopathology. Actual correlation between type-2B ( - Fig. 3A) and highgrade intramucosal dysplasia ( $\boldsymbol{- \text { Fig. }}$ 3B) was found only in five patients with a sensitivity of $83 \%$, specificity of $90 \%$, and accuracy of $90 \%$.

JNET type 3 showed specificity of $98 \%$ and diagnostic accuracy of $97 \%$. The type- 3 pattern detected in nine lesions, out of this seven came out to be SM-d cancer and 2 with noncancerous. Correlation of type 3 and SM-d cancer was seen in 7 lesions only with a sensitivity of $88 \%$, specificity of $98 \%$, and diagnostic accuracy of $97 \%$, indicating that JNET type 3 correlated with the pathological diagnosis of SM-d lesions that require surgical resection.

In a Japanese study, moderate interobserver agreement was observed among the three observers (vessel/surface pattern $\mathrm{K}$ values $=0.52 / 0.52$ ). The complete concordance rate for vessel and surface patterns among the three observers was $67 \%$. In contrast, the intraobserver agreement was excellent (vessel/surface pattern $\mathrm{k}$ values $=0.87 / 0.88) .{ }^{22}$ In this study, interobserver agreement was observed among the two observers, as kappa values $=0.76$ which suggest substantial agreement. In contrast, the intraobserver agreement was excellent, as kappa values $=0.93$. A recent meta-analysis of RCT in 2019, included 11 trials comprising 4,491 patients and 6,636 polyps that fit their criteria. Adenomas were detected in a higher percentage of patients examined with NBI compared with WLE (45.2 vs. $42.3 \%$; odds ratio [OR] $=1.14$; $95 \%$ 
confidence interval [CI]: 1.01-1.29). The effect of NBI on adenoma detection was much greater when patient bowel preparation could be described as "best" ( $\mathrm{OR}=1.3 ; 95 \% \mathrm{CI}$ : 1.04-1.62) compared with when it was categorized as just "adequate" (OR = 1.07; 95\% CI: 0.92-1.24). NBI was also more successful at detecting nonadenomatous polyps $(\mathrm{OR}=1.24$; 95\% CI: $1.06-1.44$ ) and flat polyps (OR $=1.24 ; 95 \%$ CI: $1.02-$ 1.51) compared with white light endoscopy (WLE). ${ }^{24}$

\section{Limitations}

When interpreting the results from our study, one needs to keep in mind its limitations. This was a single centered study with a small sample size of approximately 80 patients. This study was conducted in a tertiary referral center and would have thus included a select set of patients due to a referral bias, the results of which may not be generalizable outside of this environment. This was an uncontrolled study, and the number of detected cancers was small. Therefore, in the near future we need to compare the diagnostic performance of magnification NBI with other conventional endoscopy methods (e.g., chromoendoscopy) dealing with a substantial number of early colorectal cancer cases. Low magnification was used in our study which appears a major limitation since high magnification was not available to us at site of study. At present, the optical zoom magnifying endoscope is not widely used in clinical practice; however, recently the use of magnification has been increasing step by step all over the world. Future studies in NBI need to use optical high-end magnification scopes for characterization of lesions which may help contribute to better diagnostic accuracy. NBI studies also need to prove cost effectiveness when compared with conventional white light endoscopy in identifying precancerous lesions. There is need to bring in adequate modifications in the current list of accessories used for NBI which can contribute to adequate specimen for the histopathologist to comment. We need long-term multicenter randomized studies to compare NBI studies with conventional white light endoscopy in routine surveillance colonoscopies and studying the long term outcomes (at least 10 years) which might contribute to substantial results.

\section{Conclusion}

To conclude, JNET classification was found to be very useful for predicting the histology of colorectal polyps (type-1, $-2 \mathrm{~A}$, and -3 polyps). It did not correlate with HP findings in type-2B lesions in this study, which suggest that ability of type $2 \mathrm{~B}$ to identify HGD or SM-s carcinoma is not significant. Owing to slightly lower sensitivity for type $2 \mathrm{~B}$, it needs additional investigation using pit pattern diagnosis. The JNET type-2B lesions encompass a variety of colorectal tumors and majority of these exhibit type-2A/2B borderline findings. In such cases, endoscopists should perform magnifying chromoendoscopy followed by a pit pattern diagnosis.

\section{Conflict of Interest}

None declared.

\section{References}

1 Colucci PM, Yale SH, Rall CJ. Colorectal polyps. Clin Med Res 2003;1(3):261-262

2 Lieberman DA, Rex DK, Winawer SJ, Giardiello FM, Johnson DA, Levin TR. Guidelines for colonoscopy surveillance after screening and polypectomy: a consensus update by the US MultiSociety Task Force on Colorectal Cancer. Gastroenterology 2012;143(3):844-857

3 Haggar FA, Boushey RP. Colorectal cancer epidemiology: incidence, mortality, survival, and risk factors. Clin Colon Rectal Surg 2009;22(4):191-197

4 Zauber AG, Winawer SJ, O'Brien MJ, et al. Colonoscopic polypectomy and long-term prevention of colorectal-cancer deaths. N Engl J Med 2012;366(8):687-696

5 Neugut AI, Jacobson JS, Rella VA. Prevalence and incidence of colorectal adenomas and cancer in asymptomatic persons. Gastrointest Endosc Clin N Am 1997;7(3):387-399

6 Gono K, Obi T, Yamaguchi M, et al. Appearance of enhanced tissue features in narrow-band endoscopic imaging. J Biomed Opt 2004;9(3):568-577

7 Iwatate M, Ikumoto T, Hattori S, Sano W, Sano Y, Fujimori T. NBI and NBI combined with magnifying colonoscopy. Diagn Ther Endosc 2012;2012:173269

8 Hewett DG, Kaltenbach T, Sano Y, et al. Validation of a simple classification system for endoscopic diagnosis of small colorectal polyps using narrow-band imaging. Gastroenterology 2012;143(3):599-607.e1

9 Hayashi N, Tanaka S, Hewett DG, et al. Endoscopic prediction of deep submucosal invasive carcinoma: validation of the narrow-band imaging international colorectal endoscopic (NICE) classification. Gastrointest Endosc 2013;78(4):625-632

10 Hattori S, Iwatate M, Sano W, et al. Narrow-band imaging observation of colorectal lesions using NICE classification to avoid discarding significant lesions. World J Gastrointest Endosc 2014;6(12):600-605

11 Rees CJ, Rajasekhar PT, Wilson A, et al. Narrow band imaging optical diagnosis of small colorectal polyps in routine clinical practice: the detect inspect characterise resect and discard 2 (DISCARD 2) study. Gut 2017;66(5):887-895

12 Sano Y, Tanaka S, Kudo SE, et al. Narrow-band imaging (NBI) magnifying endoscopic classification of colorectal tumors proposed by the Japan NBI Expert Team. Dig Endosc 2016;28(5): 526-533

13 Higashi R, Uraoka T, Kato J, et al. Diagnostic accuracy of narrow-band imaging and pit pattern analysis significantly improved for less-experienced endoscopists after an expanded training program. Gastrointest Endosc 2010;72(1):127-135

14 Sano Y, Ikematsu H, Fu KI, et al. Meshed capillary vessels by use of narrow-band imaging for differential diagnosis of small colorectal polyps. Gastrointest Endosc 2009;69(2):278-283

15 Imperiale TF, Wagner DR, Lin CY, Larkin GN, Rogge JD, Ransohoff DF. Risk of advanced proximal neoplasms in asymptomatic adults according to the distal colorectal findings. N Engl J Med 2000;343(3):169-174

16 Lash RH, Genta RM, Schuler CM. Sessile serrated adenomas: prevalence of dysplasia and carcinoma in 2139 patients. J Clin Pathol 2010;63(8):681-686

17 Anderson JC, Rangasamy P, Rustagi T, et al. Risk factors for sessile serrated adenomas. J Clin Gastroenterol 2011;45(8):694-699

18 Tischendorf JJ, Wasmuth HE, Koch A, Hecker H, Trautwein C, Winograd R. Value of magnifying chromoendoscopy and narrow band imaging (NBI) in classifying colorectal polyps: a prospective controlled study. Endoscopy 2007;39(12):1092-1096

19 Ikematsu H, Matsuda T, Emura F, et al. Efficacy of capillary pattern type IIIA/IIIB by magnifying narrow band imaging for estimating depth of invasion of early colorectal neoplasms. BMC Gastroenterol 2010;10:33 
20 The Paris endoscopic classification of superficial neoplastic lesions: esophagus, stomach, and colon: November 30 to December 1, 2002. Gastrointest Endosc 2003;58(6(Suppl): S3-S43

21 Rutter MD, Chattree A, Barbour JA, et al. British Society of Gastroenterology/Association of Coloproctologists of Great Britain and Ireland guidelines for the management of large non-pedunculated colorectal polyps. Gut 2015;64(12): 1847-1873

22 Komeda Y, Kashida H, Sakurai T, et al. Magnifying narrow band imaging (NBI) for the diagnosis of localized colorectal lesions Using the Japan NBI expert team (JNET) classification. Oncology 2017;93(suppl 1):49-54

23 Sumimoto K, Tanaka S, Shigita K, et al. Clinical impact and characteristics of the narrow-band imaging magnifying endoscopic classification of colorectal tumors proposed by the Japan NBI Expert Team. Gastrointest Endosc 2017;85(4):816-821

24 Atkinson NSS, Ket S, Bassett P, et al. Narrow-band imaging for detection of neoplasia at colonoscopy: A meta-analysis of data from individual patients in randomized controlled trials. Gastroenterology 2019;157(2):462-471 